\title{
Disseminated Tumor Cells Predict Efficacy of Regional Nodal Irradiation in Early Stage Breast Cancer
}

\author{
Fabien Mignot, MD, ${ }^{*}$ Delphine Loirat, MD, Sylvain Dureau, PharmD, ${ }^{\dagger}$ \\ Guillaume Bataillon, MD, Martial Caly, MD, \\ Anne Vincent-Salomon, MD, Frédérique Berger, MSc, ${ }^{\ddagger}$ \\ Alain Fourquet, MD, PhD, * Jean-Yves Pierga, MD, PhD, ${ }^{\dagger} \|, \pi$ \\ Youlia M. Kirova, MD, PhD, ${ }^{*}$ and Francois-Clément Bidard, MD, PhD ${ }^{\dagger,}, \#$

\begin{abstract}
*Department of Radiation Oncology, Institut Curie, PSL Research University, Paris, France; ${ }^{\dagger}$ Department of Medical Oncology, Institut Curie, PSL Research University, Paris and Saint Cloud, France; ${ }^{\ddagger}$ Department of Biostatistics, Institut Curie, PSL Research University, Saint Cloud, France; ${ }^{\S}$ Department of Pathology, Institut Curie, PSL Research University, Paris, France; "Circulating Tumor Biomarkers Laboratory, Siric, Institut Curie, PSL Research University, Paris, France; "Université Paris Descartes, Paris, France; and "UVSQ, Paris Saclay University, Paris, France
\end{abstract}

Received May 14, 2018. Accepted for publication Sep 25, 2018.

Summary

This long-term analysis (median follow-up,

11.7 years) confirms the predictive impact of disseminated tumor cell (DTC) status on the efficacy of regional radiation therapy for locoregional relapse in early breast cancer. This study also confirms that DTC is an independent prognostic factor for locoregional relapse.

These data can be used to

\begin{abstract}
Purpose: Disseminated tumor cells (DTCs) collect in the bone marrow and indicate micrometastatic spread. We previously reported that DTCs could be a predictive factor for the efficacy of regional node irradiation (internal mammary nodes [IMNs]/supraand infraclavicular nodes [SCNs]). In this article, we report the long-term results ( $>10$ years) on the impact of DTC status in early stage breast cancer.

Methods and Materials: Patients with localized breast cancer were eligible for inclusion in this prospective cohort. DTCs were obtained from a medullary iliac crest sample performed before any primary therapy. DTC status was prospectively assessed by pathologists. Irradiation volumes were defined per standard of care. Cumulative incidence rates and hazard ratios were obtained using both Cox and Fine-Gray models. Interaction tests were performed to confirm the predictive value of DTC status in a multivariate analysis.

Results: Six hundred twenty patients with localized breast cancer were included. Overall, 94 patients (15.2\%) were DTC-positive. After a median follow-up of

This article was the subject of an oral presentation at the $59^{\text {th }}$ annual meeting of the American Society for Radiation Oncology (ASTRO) (San Diego Convention Center [USA], September 24, 2017).

Conflict of interest: none.

Supplementary material for this article can be found at https://doi.org/ 10.1016/j.ijrobp.2018.09.033.
\end{abstract}

Reprint requests to: Youlia Kirova, MD, PhD, Department of Radiation Oncology, Institut Curie, 26 rue d'Ulm, 75005 Paris, France. Tel: +33 144 324 000; E-mail: youlia.kirova@curie.fr

Youlia M. Kirova and Francois-Clement Bidard made equal contributions to this study. 4654). 
conduct a prospective comparative study based on DTC or circulating tumor cells detection to determine whether it could constitute a predictive marker, allowing better selection of patients for regional irradiation.
11.7 years, 47 patients $(7.6 \%)$ experienced locoregional relapse. DTC detection was associated with a higher risk of locoregional relapse in univariate and multivariate analyses (Cox hazard ratio, 3.26; 95\% confidence interval, 1.6-5.7; $P=.001$ ). In the multivariate subgroup analysis, IMN/SCN irradiation significantly reduced locoregional relapse among DTC-positive patients compared with DTC-negative patients (interaction test: hazard ratio, $0.3 ; 95 \%$ confidence interval, $0.1-0.9 ; P=.02$ ). IMN/SCN was the only irradiation volume with an impact on locoregional relapse in patients according to DTC status, and the predictive value of DTC status for the benefit of locoregional irradiation was independent of locoregional nodal status.

Conclusions: This long-term analysis confirms the predictive impact of DTC status on the efficacy of regional radiation therapy for locoregional relapse in early breast cancer. After further studies, DTC status could be used as a decision tool to better tailor adjuvant radiation therapy in patients with early stage breast cancer. (C) 2018 Elsevier Inc. All rights reserved.

\section{Introduction}

Disseminated tumor cells (DTCs) and circulating tumor cells (CTCs) are isolated cancer cells detected in bone marrow and blood, respectively. In patients with breast cancer without distant metastasis, the DTC detection rate (by immunocytology-based methods) is around $10 \%$ to $30 \% .^{1-4}$ Although these tumor cells do not systematically develop into distant metastases, their detection has been repeatedly associated with a higher risk of distant relapse and poorer patient outcomes. ${ }^{1-3,5-8}$ To acknowledge this prognostic impact, the 7th TNM classification of breast cancer introduced the $\mathrm{cM} 0(\mathrm{i}+)$ category, defined by the presence of DTCs or CTCs detected in a patient with no overt distant metastasis. ${ }^{9}$

Recent discussion has focused on the benefits of regional nodal irradiation (supra- and infraclavicular nodes [SCNs] and internal mammary node [IMNs]) irradiation in early stage breast cancer. Large-scale phase 3 randomized studies have demonstrated that SCN/IMN irradiation decreased the risk of locoregional and distant relapse. Distant disease-free survival and disease-free survival were also improved in the regional nodal irradiation group, but this irradiation increased the risk of pulmonary and cardiac fibrosis, as well as long-term skin toxicity. ${ }^{10,11}$ More reliable factors for the selection of patients who should receive regional irradiation must be identified, and the decision to perform SCN/IMN radiation remains debated in current practice.

In a first analysis published in 2009 , with a short median follow-up of 56 months, we observed that DTC-positive $(\mathrm{DTC}+)$ patients were at higher risk of locoregional relapse, confirming that DTC status was an independent prognostic factor in early stage breast cancer. ${ }^{12}$ Similar findings have been more recently reported in CTC-positive patients. $^{13}$ More importantly, we observed that DTC + patients with no SCN/IMN irradiation had a high locoregional relapse rate, whereas DTC + patients with SCN/IMN irradiation had a low risk of locoregional relapse, similar to that observed in DTC-negative (DTC-) patients. $^{12}$

In this article, we report the long-term results on the impact of DTC status as a predictive factor for the efficacy of regional nodal irradiation.

\section{Methods and Materials}

\section{Study population}

This prospective cohort was approved by the regional ethics committee. Eligibility criteria were women with histologically proven nonmetastatic unilateral breast adenocarcinoma (stage I-III; American Joint Committee on Cancer 5th edition breast cancer staging) ${ }^{14}$; age $>18$ years; treatment at Institut Curie (Paris, France); no history of previous malignancy (except in situ carcinoma of the cervix or nonmelanoma skin cancer); and signed informed consent. Patient and tumor characteristics were recorded prospectively in the patients' medical charts, except for HER2 status, which was assessed retrospectively.

\section{Bone marrow status}

Bone marrow sampling by anterior iliac crest aspiration for DTC detection was performed during breast surgery or before initiation of neoadjuvant chemotherapy. Samples were processed, and mononuclear cells were collected and stained using the pancytokeratin mAb A45-B/B3 (Micromet, Munich, Germany; Chromavision, San Juan, CA), as previously described. ${ }^{2,15}$

DTC status was assessed prospectively by experienced pathologists after immunocytostaining. Only cytokeratinpositive cells with atypical cytologic features were classified as DTC + by experienced pathologists according to the European Working Group for standardization of tumor cell detection. ${ }^{16}$ Patients and clinicians both remained blinded to the results of bone marrow analysis. 


\section{Treatment regimens and follow-up}

Treatment decisions were not based on DTC status. All patients underwent breast surgery (either breast-conserving surgery or mastectomy); axillary dissection was performed in the presence of lymph node involvement or positive sentinel lymph node biopsy. Patients at high risk of relapse received anthracycline- and docetaxel-based neoadjuvant and/or adjuvant chemotherapy, according to institutional guidelines. Hormone therapy was delivered to patients with estrogen receptor-positive tumors.

Radiation therapy was performed after surgery or adjuvant chemotherapy to a total dose of 50 Gy in 25 fractions to the whole breast or chest wall, with or without lymph nodes. A boost dose of 16 Gy could be delivered to tumor bed in women under the age of 60 years or with grade 3 tumor, high proliferation index, or lymphovascular invasion (LVI).

SCN/IMN irradiation was indicated in the case of lymph node involvement or, for internal or central tumors, when at least 2 of the following factors were present: age $<40$ years, presence of LVI, or tumor size $>2 \mathrm{~cm}$. The low axilla (level I) was irradiated only in the presence of massive lymph node involvement $(>50 \%$ after axillary lymph node dissection). The IMN region was treated by a mixed photon-electron technique. Whole breast or chest wall and SCN/axillary regions were irradiated, using previously described techniques set up at Institut Curie. ${ }^{17-19}$

Follow-up was performed at Institut Curie for the first 5 years after treatment and included clinical examination every 6 months and annual bilateral mammography. Breast cancer relapses were prospectively recorded. Annual follow-up was ensured after the first 5 years.

\section{Statistical analysis}

The first objective of this prospective study was to assess the impact of DTC detection on disease-free survival; the impact on locoregional relapse-free interval (LRFI) was an exploratory endpoint with no prespecified statistical power. Locoregional relapses were defined as documented invasive breast cancer recurrence in ipsilateral breast, chest wall, or regional lymph nodes (axillary nodes, SCNs, or IMNs) before any distant metastatic relapse. Overall survival (OS) was defined as the time from surgery to death from any cause. Breast cancer-specific survival (BCSS) was calculated by only taking into account deaths from breast cancer (patients who died from other causes were censored at the date of death). LRFI was defined as the time interval between surgery and any locoregional relapse; patients experiencing distant metastatic relapse were censored at the time of metastatic relapse. Patients still alive with no breast cancer relapse were censored at the date of last news.

Quantitative data were expressed as the mean and range, and qualitative data were expressed as numbers and proportions; missing data were not taken into account. LRFI,
OS, and BCSS were estimated according to the KaplanMeier method and compared using the log-rank test. Variables significant at the $10 \%$ level on univariate analysis were included in a multivariate Cox proportional hazard model to determine the clinical variables associated with OS and BCSS.

Because death is a competing risk for locoregional relapse, assessment of the risk of locoregional relapse based on survival analysis was performed according to methodologic recommendations for competing risks frameworks, using cumulative incidence functions, models for cause-specific hazards ratio, and subdistribution hazards ratio. ${ }^{20} \mathrm{~A}$ Cox model was used for regression on causespecific hazards ratios, whereas a Fine-Gray model was used for regression on sub-distribution hazards ratios. ${ }^{21,22}$ The cumulative incidence of LR was estimated and displayed in 2 different ways: by using the complement of the Kaplan-Meier product estimator (1-KM) and by using the Fine-Gray method for competing risks. All statistical analyses were performed with $\mathrm{R}$ software (version 3.22; https://cran.r-project.org/). The limit of significance was defined as $P<.05$.

\section{Results}

Six hundred twenty women with early stage invasive breast cancer were included in this cohort. In this series, $93 \%$ of patients $(\mathrm{n}=575)$ received adjuvant radiation therapy (Table 1), 65\% received SCN/IMN irradiation, and $21 \%$ received axillary irradiation. An additional boost to the tumor bed was delivered to 280 patients (45\%). Pathologic positive lymph nodes $(\mathrm{pN}+$ ) were observed in 323 patients (52\%); as expected, positive lymph node status influenced the SCN/IMN irradiation rate: $41 \%$ and $87 \%$ of pN0 and $\mathrm{pN}+$ patients received SCN/IMN irradiation, respectively $(P<.001)$. Likewise, adjuvant chemotherapy was administered to $26 \%$ and $82 \%$ of $\mathrm{pNO}$ and $\mathrm{pN}+$ patients, respectively $(P<.001)$. The DTC detection rate was $15.2 \%$ $(\mathrm{n}=94)$, and no significant correlation was observed among patient characteristics, treatments, and DTC status (Table 1). No correlation was observed between irradiation volumes and DTC status (Table 2).

With a median follow-up of 11.7 years (range, 0.1-16.7), 47 patients (7.6\%) experienced locoregional relapse as first event. Most relapses occurred in the breast or chest wall (72.3\% of locoregional relapses). Details on the site of relapse are shown in Table E1 (available online at https:// doi.org/10.1016/j.ijrobp.2018.09.033). Long-term analysis confirmed the role of DTC status as an independent prognostic factor for locoregional relapse. LRFI was significantly shorter in DTC+ patients compared with DTCpatients in both univariate (hazard ratio [HR], 2.8; 95\% confidence interval $[\mathrm{CI}], 1.5-5.3 ; P=.001)$ and multivariate analyses (HR, 3.26; 95\% CI, 1.6-5.7; $P=.001)$ (Table 3). The 10-year locoregional relapse was $10 \%$ in DTC - patients versus 20\% in DTC + patients (Fig. 1). 
Table 1 Patient characteristics, treatments, and DTC detection rate

\begin{tabular}{|c|c|c|c|}
\hline Patient characteristics & $\begin{array}{l}\text { No. of } \\
\text { patients }\end{array}$ & $\begin{array}{l}\text { DTC detection } \\
\text { rate }\end{array}$ & $P$ value \\
\hline Age $(y)$ & & & .5 \\
\hline$<45$ & 103 & $17.5 \%$ & \\
\hline$\geq 45$ & 517 & $14.7 \%$ & \\
\hline $\mathrm{cT}$ & & & .2 \\
\hline 1 & 325 & $17.5 \%$ & \\
\hline 2 & 172 & $12.2 \%$ & \\
\hline $3 / 4$ & 123 & $13 \%$ & \\
\hline $\mathrm{pN}$ & & & .8 \\
\hline Negative & 295 & $15.6 \%$ & \\
\hline Positive & 323 & $14.9 \%$ & \\
\hline Histology & & & .3 \\
\hline Ductal & 513 & $14.5 \%$ & \\
\hline Lobular & 75 & $16 \%$ & \\
\hline Tumor grade & & & .3 \\
\hline 1 & 203 & $14.8 \%$ & \\
\hline 2 & 235 & $14.9 \%$ & \\
\hline 3 & 163 & $15.3 \%$ & \\
\hline HR status & & & .4 \\
\hline Positive & 496 & $14.5 \%$ & \\
\hline Negative & 115 & $17.4 \%$ & \\
\hline LVI & & & .3 \\
\hline No & 411 & $13.6 \%$ & \\
\hline Yes & 189 & $18 \%$ & \\
\hline Surgery & & & .6 \\
\hline Lumpectomy & 448 & $15 \%$ & \\
\hline Mastectomy & 165 & $15.2 \%$ & \\
\hline RT (all modalities) & & & .3 \\
\hline Yes & 575 & $14.7 \%$ & \\
\hline No & 42 & $20.9 \%$ & \\
\hline Breast/chest wall RT & & & .5 \\
\hline Yes & 572 & $14.8 \%$ & \\
\hline No & 45 & $20.9 \%$ & \\
\hline Boost RT & & & 1 \\
\hline Yes & 280 & $15.2 \%$ & \\
\hline No & 337 & $15.1 \%$ & \\
\hline SCN/IMN RT & & & 1 \\
\hline Yes & 375 & $15.1 \%$ & \\
\hline No & 242 & $15.2 \%$ & \\
\hline Axillary RT & & & .8 \\
\hline Yes & 119 & $15.1 \%$ & \\
\hline No & 498 & $15.2 \%$ & \\
\hline Chemotherapy & & & .7 \\
\hline Yes & 346 & $15.7 \%$ & \\
\hline No & 273 & $14.5 \%$ & \\
\hline Hormone therapy & & & 1 \\
\hline Yes & 401 & $14.9 \%$ & \\
\hline No & 219 & $16.2 \%$ & \\
\hline
\end{tabular}

Abbreviations: DTC $=$ disseminated tumor cell; $\mathrm{HR}=$ hormone receptors; LVI = lymphovascular invasion; RT = radiation therapy; SCN/IMN = supra- and infraclavicular and internal mammary nodes.

We then examined the interaction between SCN/IMN irradiation and DTC status in terms of LRFI. We found that SCN/IMN irradiation was associated with significant risk reduction in DTC + patients (estimated by the Fine and
Gray Model: HR, 0.29; 95\% CI, 0.1-0.9; $P=.02)$, but had no obvious effect in DTC- patients (Fig. 2). Similar results were observed when using the complement of the KaplanMeier estimator (ie, without considering death relapses as competitive events) and a Cox model. Interestingly, analysis limited to the subgroup of $\mathrm{pN} 0$ patients demonstrated a similar amplitude of risk reduction (Fine and Gray model: HR, 0.14; 95\% CI, 0.02-1.18; $P=.07$; Fig. E1A, available online at https://doi.org/10.1016/j.ijrobp.2018.09.033). In contrast, for $\mathrm{pN}+$ patients, DTC status had no significant impact on SCN/IMN irradiation efficiency (HR, 0.48; 95\% CI, $0.09-2.45 ; P=.38$; Fig. E1B, available online at https://doi.org/10.1016/j.ijrobp.2018.09.033). This effect was not observed with any of the other radiation fields or any of the other treatment modalities (chemotherapy, hormone therapy) (Table E2; available online at https://doi.org/ 10.1016/j.ijrobp.2018.09.033).

In terms of OS and BCSS, 152 patients (24.5\%) had died at the time of analysis, and 121 of these deaths (79.6\%) were from breast cancer. Univariate analysis showed that DTC status was a prognostic factor for BCSS $(P=.04$; Fig. E2, available online at https://doi.org/10.1016/j.ijrobp. 2018.09.033), but not for OS ( $P=.09$; Fig. E3, available online at https://doi.org/10.1016/j.ijrobp.2018.09.033). On multivariate analysis, DTC positivity at baseline was associated with significantly shorter BCSS (HR, 1.9; 95\% CI, 1.2-3.0; $P=.01)$, together with large tumor size $(P<.001)$, grade $2 / 3(P<.001)$, negative hormone receptor status $(P<.001)$ and axillary lymph node involvement $(P<.001$; Table 4$)$.

\section{Discussion}

To our knowledge, no biologic or genomic criteria are available to predict the efficacy of irradiation fields in early breast cancer. In this cohort, the DTC detection rate was in the range of that in other recent reports. ${ }^{23}$ We have previously reported that DTC + patients derived benefit from regional irradiation, with a short median follow-up of 56 months $(P=.028) .^{12}$ The present study confirms these results, with a median long-term follow-up of 11.7 years. We also report a nonstatistically significant trend toward a predictive impact of DTC status in $\mathrm{pN0}$ patients. This study also confirms that DTC is an independent prognostic factor for locoregional relapse. Hartkopf et al recently reported an increased risk of locoregional relapse in DTC + patients (multivariate analysis: HR, 1.65; 95\% CI, 1.13-2.40; $P=.009)$ in a series of 3072 patients with a median follow-up of 44 months. ${ }^{24}$ The prognostic impact of DTC on locoregional relapse observed in our study remained significant in the long term and is consistent with the literature.

A potential limitation of our findings concerns the heterogeneous treatments used during cohort inclusion, particularly in relation to anti-HER2 therapies, considering most patients were treated in the pre-trastuzumab era. 
Table 2 Treatments according to $\mathrm{pN}$ status and DTC status

\begin{tabular}{|c|c|c|c|c|c|c|}
\hline & pN0 $(n=295)$ & $\mathrm{pN}+(\mathrm{n}=323)$ & $P$ value & $\mathrm{DTC}-(\mathrm{n}=526)$ & $\mathrm{DTC}+(\mathrm{n}=94)$ & $P$ value \\
\hline \multicolumn{7}{|l|}{ Surgery } \\
\hline Lumpectomy & $252(85.4 \%)$ & $195(60.4 \%)$ & .006 & $381(72.4 \%)$ & $67(71.3 \%)$ & 1 \\
\hline Mastectomy & $41(13.9 \%)$ & $123(38.1 \%)$ & $<.001$ & $141(26.8 \%)$ & $25(26.6 \%)$ & 1 \\
\hline RT (all modalities) & $272(92.2 \%)$ & $304(94.1 \%)$ & .8 & $492(93.5 \%)$ & $85(90.4 \%)$ & .9 \\
\hline Breast/chest wall RT & $271(99.6 \%)$ & $300(93.9 \%)$ & .9 & $487(92.6 \%)$ & $85(100 \%)$ & .9 \\
\hline Boost RT & $146(53.7 \%)$ & $134(41.5 \%)$ & .3 & $237(45.1 \%)$ & $43(50.6 \%)$ & .9 \\
\hline SCN/IMN RT & $112(41.2 \%)$ & $262(81.1 \%)$ & $<.001$ & $318(60.5 \%)$ & $57(67.1 \%)$ & 1 \\
\hline Axillary RT & $9(3.3 \%)$ & $109(35.9 \%)$ & $<.001$ & $101(20.5)$ & $18(21.2 \%)$ & 1 \\
\hline Chemotherapy & $79(26.8 \%)$ & $266(87.2 \%)$ & $<.001$ & $293(55.7 \%)$ & $54(63.5 \%)$ & .9 \\
\hline Hormone therapy & $171(58.0 \%)$ & $230(71.2 \%)$ & .1 & $343(65.2 \%)$ & $60(63.8 \%)$ & .9 \\
\hline
\end{tabular}

Table 3 Multivariate analysis on locoregional relapse-free interval

\begin{tabular}{|c|c|c|}
\hline Patient characteristics & HR $(95 \%$ CI) & $P$ value \\
\hline \multicolumn{3}{|l|}{ DTC status } \\
\hline Positive & $3.26(1.6-5.7)$ & .001 \\
\hline Negative & 1 & \\
\hline \multicolumn{3}{|l|}{ Age $(y)$} \\
\hline$\geq 45$ & $0.73(0.28-1.88)$ & .51 \\
\hline$<45$ & 1 & \\
\hline \multicolumn{3}{|l|}{$\mathrm{cT}$} \\
\hline 1 & 1 & \\
\hline 2 & $1.08(0.49-2.36)$ & .85 \\
\hline $3 / 4$ & $1.27(0.35-4.60)$ & .71 \\
\hline \multicolumn{3}{|l|}{$\mathrm{pN}$} \\
\hline Positive & $1.11(0.59-2.07)$ & .74 \\
\hline Negative & 1 & \\
\hline \multicolumn{3}{|l|}{ Histology } \\
\hline Ductal & 1 & \\
\hline Lobular & $1.08(0.40-2.93)$ & .88 \\
\hline \multicolumn{3}{|l|}{ Tumor grade } \\
\hline 1 & 1 & \\
\hline 2 & $1.76(0.83-3.69)$ & .14 \\
\hline 3 & $1.70(0.62-4.71)$ & .30 \\
\hline \multicolumn{3}{|l|}{ HR status } \\
\hline Positive & $2.52(0.82-7.79)$ & .11 \\
\hline Negative & 1 & \\
\hline \multicolumn{3}{|l|}{ LVI } \\
\hline No & 1 & \\
\hline Yes & $1.58(0.75-3.36)$ & .23 \\
\hline \multicolumn{3}{|l|}{ RT (all modalities) } \\
\hline Yes & $0.50(0.14-1.83)$ & .29 \\
\hline No & 1 & \\
\hline \multicolumn{3}{|l|}{ Chemotherapy } \\
\hline Yes & $0.78(0.31-2.01)$ & .61 \\
\hline No & 1 & \\
\hline \multicolumn{3}{|l|}{ Hormone therapy } \\
\hline Yes & $0.45(0.22-0.94)$ & .03 \\
\hline No & 1 & \\
\hline
\end{tabular}

Abbreviations: $\mathrm{CI}=$ confidence interval; DTC $=$ disseminated tumor cell; HR = hormone receptors; LVI = lymphovascular invasion; $\mathrm{RT}=$ radiation therapy.
However, radiation therapy (radiation technique and dose) was homogeneous over time. In addition, DTC status was unknown to clinicians for chemotherapy and radiation volume decision making.

The benefits of regional nodal irradiation (SCNs/IMNs) have recently been questioned. According to the St Gallen international breast cancer guidelines, regional irradiation is indicated in patients with $\mathrm{pN} 1$ cancers (1-3 positive nodes) and adverse clinical features, including young age ( $\leq 40$ years), adverse biology such as low or negative estrogen receptor expression, high grade, extensive LVI, and all patients with 4 or more positive lymph nodes. ${ }^{25}$ Two recent phase 3 randomized studies have provided concrete evidence in support of these guidelines. Whelan et al demonstrated that SCN/IMN irradiation decreased the risk of locoregional and distant relapse but did not affect BCSS and OS. ${ }^{10}$ The European Organisation for Research and

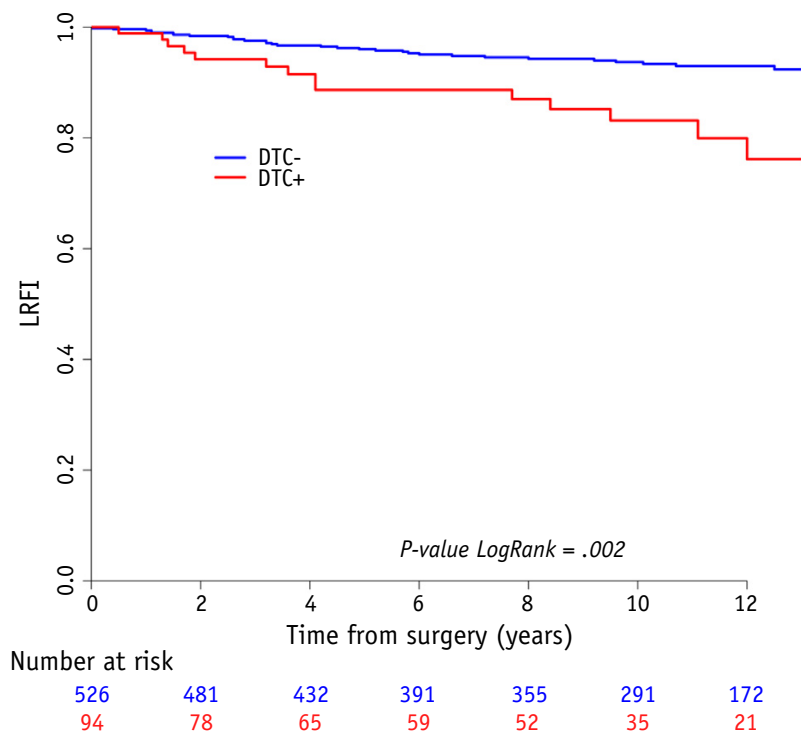

Fig. 1. Locoregional relapse-free interval according to disseminated tumor cell status estimated by the KaplanMeier method. 


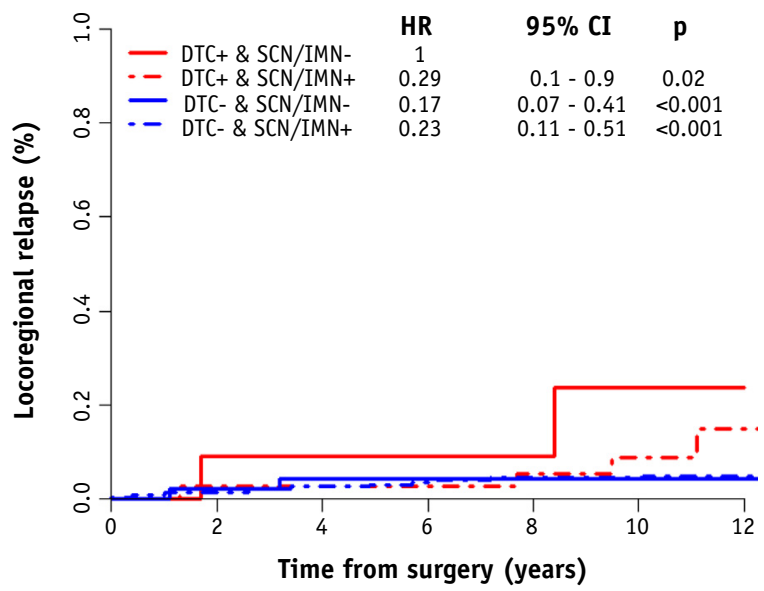

$\begin{array}{ccccccc}\text { Number at risk } & & & & & & \\ -11 & 8 & 7 & 6 & 5 & 3 & 1 \\ -37 & 29 & 23 & 20 & 18 & 9 & 7 \\ -47 & 41 & 35 & 30 & 24 & 19 & 8 \\ -225 & 200 & 176 & 156 & 141 & 118 & 82\end{array}$

Fig. 2. Cumulative incidence of locoregional relapses according to DTC status and SCN/IMN irradiation based on the sub-distribution hazard and considering death as competitive events. Abbreviations: DTC $=$ disseminated tumor cell; DTC $-=$ DTC negative; DTC $+=$ DTC positive; IMN = supra- and infraclavicular nodes/internal mammary node; SCN/IMN+ = Radiation therapy to SCNs/IMNs; SCN/IMN- = No radiation therapy to SCNs/ IMNs.

Treatment of Cancer trial conducted in 4004 patients demonstrated a significant improvement of BCSS and a decreased risk of relapse. ${ }^{11}$ In these 2 trials, SCN/IMN irradiation had no impact on OS, but a significant increase in pulmonary and cardiac toxicity was observed. In a Danish cohort of 3089 patients with early node-positive breast cancer, IMN irradiation (for right breast cancer) improved survival compared to no IMN irradiation (for left breast cancer) with no increased cardiac toxicity. ${ }^{26} \mathrm{~A}$ French randomized trial did not demonstrate any significant survival benefit in IMN-irradiated patients, but had some methodologic limitations. ${ }^{27}$ Regional irradiation decisions are, therefore, based on clinical and pathologic criteria and remain a subject of debate, particularly in $\mathrm{pNO}$ patients. Better patient selection in order to personalize irradiation volumes therefore constitutes a major challenge.

The biologic link between DTC detection in bone marrow and locoregional relapse is unknown. DTC appears as a marker of higher disease burden within the locoregional volumes that hormone therapy or chemotherapy could not adequately manage. Tumor "self-seeding" could also be a further explanation. In this model, some cancer cells from the primary tumor acquire the ability to intravasate into the circulation, stop in a sanctuary organ such as bone marrow or lymph nodes, and enter into quiescence. ${ }^{28-30}$ These cells can subsequently reseed the initial tumor site. ${ }^{31-33}$ Cancer cells can therefore escape local treatment by surgery and radiation therapy and subsequently reinitiate tumor growth at the initial tumor site, possibly guided by locally released chemokines and growth factors during the wound healing process after breast surgery. SCN/IMN irradiation would kill quiescent DTCs located in the sternal bone marrow and lymph node sanctuary areas. Regional irradiation would therefore provide a benefit in DTC + patients, in contrast with DTC - patients. Interestingly, in addition to our study based on DTC detection (in bone marrow), data reported by Goodman et al have

Table 4 Multivariate analysis on overall survival and breast cancer-specific survival estimated by Cox regression model for causespecific HRs

\begin{tabular}{|c|c|c|c|c|}
\hline \multirow[b]{2}{*}{ Patient characteristics } & \multicolumn{2}{|c|}{ Overall survival } & \multicolumn{2}{|c|}{ Breast cancer-specific survival } \\
\hline & $\mathrm{HR}(95 \% \mathrm{CI})$ & $P$ value & HR $(95 \%$ CI $)$ & $P$ value \\
\hline \multicolumn{5}{|l|}{ DTC status } \\
\hline Positive & 1 & & 1 & \\
\hline Negative & $1.43(1-2.2)$ & .09 & $1.85(1.2-3)$ & .01 \\
\hline \multicolumn{5}{|l|}{$\mathrm{cT}$} \\
\hline 1 & 1 & & 1 & \\
\hline 2 & $3.1(1.8-5.2)$ & $<.001$ & $2.1(0.9-4.8)$ & .07 \\
\hline $3 / 4$ & $7.64(4.5-12.9)$ & $<.001$ & $3.9(1.7-9)$ & .002 \\
\hline \multicolumn{5}{|l|}{$\mathrm{pN}$} \\
\hline Negative & 1 & & 1 & \\
\hline Positive & $3.42(2.3-5)$ & $<.001$ & $2.2(1.3-3.8)$ & .002 \\
\hline \multicolumn{5}{|l|}{ Tumor grade } \\
\hline 1 & 1 & & 1 & \\
\hline 2 & $3.24(1.9-5.6)$ & $<.001$ & $4.41(1.9-10.4)$ & $<.001$ \\
\hline 3 & $6.04(3.6-10.3)$ & $<.001$ & $5.2(2.1-12.7)$ & $<.001$ \\
\hline \multicolumn{5}{|l|}{ HR status } \\
\hline Negative & 1 & & 1 & \\
\hline Positive & $0.34(0.2-0.5)$ & $<.001$ & $0.46(0.3-0.7)$ & $<.001$ \\
\hline
\end{tabular}


suggested a benefit of radiation therapy in patients with CTC detected in blood. ${ }^{34}$ In a cohort of 1407 patients, CTC-positive patients not receiving radiation therapy had an increased risk of mortality compared with irradiated CTC-positive patients (HR, 4.82; 95\% CI, 2.62-8.85; $P<.001)$. The authors concluded that CTC status, which is a known prognostic factor in early breast cancer, could be a useful predictive factor for the benefit of radiation therapy in early breast cancer, but irradiation fields were not specified in this CTC-based report. Although DTC and CTC do not completely overlap, ${ }^{7}$ a practical advantage of CTC detection over DTC detection is that the latter requires trained pathologists. Combining DTC and CTC detection might also lower the risk of false negative, but its clinical validity has not been properly assessed.

\section{Conclusions}

This long-term analysis confirms the predictive impact of DTC status on the efficacy of regional radiation therapy for locoregional relapse in early breast cancer. These data can be used to conduct a prospective comparative study based on DTC or CTC detection to determine whether it could constitute a predictive marker allowing better selection of patients for regional irradiation.

\section{References}

1. Janni W, Vogl FD, Wiedswang G, et al. Persistence of disseminated tumor cells in the bone marrow of breast cancer patients predicts increased risk for relapse-a European pooled analysis. Clin Cancer Res 2011;17:2967-2976.

2. Bidard F-C, Vincent-Salomon A, Gomme S, et al. Disseminated tumor cells of breast cancer patients: A strong prognostic factor for distant and local relapse. Clin Cancer Res Off J Am Assoc Cancer Res 2008; 14:3306-3311.

3. Braun S, Vogl FD, Naume B, et al. A pooled analysis of bone marrow micrometastasis in breast cancer. N Engl J Med 2005;353: 793-802.

4. Schindlbeck C, Andergassen U, Hofmann S, et al. Comparison of circulating tumor cells (CTC) in peripheral blood and disseminated tumor cells in the bone marrow (DTC-BM) of breast cancer patients. $J$ Cancer Res Clin Oncol 2013;139:1055-1062.

5. Janni WJ, Rack B, Terstappen LW, et al. Pooled analysis of the prognostic relevance of circulating tumor cells in primary breast cancer. Clin Cancer Res 2016;22:2583-2593.

6. Wiedswang G, Borgen E, Kåresen R, et al. Detection of isolated tumor cells in bone marrow is an independent prognostic factor in breast cancer. J Clin Oncol 2003;21:3469-3478.

7. Bidard FC, Proudhon C, Pierga JY. Circulating tumor cells in breast cancer. Mol Oncol 2016;10:418-430.

8. Pantel K, Hayes DF. Disseminated breast tumour cells: Biological and clinical meaning. Nat Rev Clin Oncol 2018;15:129-131.

9. Edge SB, Compton CC. The American Joint Committee on Cancer: The 7th edition of the AJCC cancer staging manual and the future of TNM. Ann Surg Oncol 2010;17:1471-1474.

10. Whelan TJ, Olivotto IA, Parulekar WR, et al. Regional nodal irradiation in early-stage breast cancer. N Engl J Med 2015;373:307316.
11. Poortmans PM, Collette S, Kirkove C, et al. Internal mammary and medial supraclavicular irradiation in breast cancer. $N$ Engl J Med 2015;373:317-327.

12. Bidard F-C, Kirova YM, Vincent-Salomon A, et al. Disseminated tumor cells and the risk of locoregional recurrence in nonmetastatic breast cancer. Ann Oncol Off J Eur Soc Med Oncol 2009;20:1836-1841.

13. Bidard FC, Michiels S, Riethdorf S, et al. Circulating tumor cells in breast cancer patients treated by neoadjuvant chemotherapy: A metaanalysis. J Natl Cancer Inst 2018;110:560-567.

14. Fleming ID, American Joint Committee on Cancer, American Cancer Society, et al. AJCC Cancer Staging Manual. 5th ed. Philadelphia, PA: Lippincott-Raven; 1997.

15. Pierga J-Y, Bonneton C, Vincent-Salomon A, et al. Clinical significance of immunocytochemical detection of tumor cells using digital microscopy in peripheral blood and bone marrow of breast cancer patients. Clin Cancer Res Off J Am Assoc Cancer Res 2004; 10:1392-1400.

16. Fehm T, Braun S, Muller V, et al. A concept for the standardized detection of disseminated tumor cells in bone marrow from patients with primary breast cancer and its clinical implementation. Cancer 2006; 107:885-892.

17. Kirova YM, Campana F, Fournier-Bidoz N, et al. Postmastectomy electron beam chest wall irradiation in women with breast cancer: A clinical step toward conformal electron therapy. Int J Radiat Oncol Biol Phys 2007;69:1139-1144.

18. Fournier-Bidoz N, Kirova YM, Campana F, et al. Simplified fieldin-field technique for a large-scale implementation in breast radiation treatment. Med Dosim Off J Am Assoc Med Dosim 2012; 37:131-137.

19. Kirova YM, Hijal T, Campana F, et al. Whole breast radiotherapy in the lateral decubitus position: A dosimetric and clinical solution to decrease the doses to the organs at risk (OAR). Radiother Oncol J Eur Soc Ther Radiol Oncol 2014;110:477-481.

20. Latouche A, Beyersmann J, Fine JP. Comments on 'Analysing and interpreting competing risk data'. Stat Med 2007;26:3676-3679.

21. Cox DR. Regression models and life-tables. J R Stat Soc Ser B Methodol 1972;34:187-220.

22. Fine JP, Gray RJ. A proportional hazards model for the subdistribution of a competing risk. J Am Stat Assoc 1999;94:496-509.

23. Vincent-Salomon A, Bidard FC, Pierga JY. Bone marrow micrometastasis in breast cancer: Review of detection methods, prognostic impact and biological issues. J Clin Pathol 2008;61:570-576.

24. Hartkopf AD, Wallwiener M, Fehm TN, et al. Disseminated tumor cells from the bone marrow of patients with nonmetastatic primary breast cancer are predictive of locoregional relapse. Ann Oncol 2015; 26:1155-1160.

25. Curigliano G, Burstein HJ, P Winer E, et al. De-escalating and escalating treatments for early-stage breast cancer: The St. Gallen International Expert Consensus Conference on the Primary Therapy of Early Breast Cancer 2017. Ann Oncol 2017; 28:1700-1712.

26. Thorsen LBJ, Offersen BV, Dan $\varnothing \mathrm{H}$, et al. DBCG-IMN: A population-based cohort study on the effect of internal mammary node irradiation in early node-positive breast cancer. J Clin Oncol 2016;34:314-320.

27. Hennequin C, Bossard N, Servagi-Vernat S, et al. Ten-year survival results of a randomized trial of irradiation of internal mammary nodes after mastectomy. Int $J$ Radiat Oncol Biol Phys 2013;86:860-866.

28. Pantel K, Müller V, Auer M, et al. Detection and clinical implications of early systemic tumor cell dissemination in breast cancer. Clin Cancer Res 2003;9:6326-6334.

29. Sosa MS, Bragado P, Aguirre-Ghiso JA. Mechanisms of disseminated cancer cell dormancy: An awakening field. Nat Rev Cancer 2014;14: 611-622.

30. Schlimok G, Funke I, Holzmann B, et al. Micrometastatic cancer cells in bone marrow: In vitro detection with anti-cytokeratin and in vivo 
labeling with anti-17-1A monoclonal antibodies. Proc Natl Acad Sci USA 1987;84:8672-8676.

31. Comen E, Norton L, Massagué J. Clinical implications of cancer selfseeding. Nat Rev Clin Oncol 2011;8:369-377.

32. Kim MY, Oskarsson T, Acharyya S, et al. Tumor self-seeding by circulating cancer cells. Cell 2009;139:1315-1326.
33. Gao XL, Zhang M, Tang YL, et al. Cancer cell dormancy: Mechanisms and implications of cancer recurrence and metastasis. Onco Targets Ther 2017;10:5219-5228.

34. Goodman CR, Seagle BL, Friedl TWP, et al. Association of circulating tumor cell status with benefit of radiotherapy and survival in earlystage breast cancer. JAMA Oncol 2018;4:e180163. 